\title{
God Beyond the Boundary-Stones of Thought
}

\author{
Abbas Ahsan
}

\begin{abstract}
In this paper I make the case for epistemic relativism: the radical view that all human knowledge/truth is relative. I extend the application of epistemic relativism to include necessary laws such as the laws of logic. I argue that the truth of such laws are relative to human thought, which are ultimately instances derived from our experiences. These experiences act as limitations to which we are conceptually bound. As a result of this, we cannot apprehend God's omnipotence. This includes God's maximal power in being able to perform logically impossible actions. Our epistemic inability to conceive of such logically impossible actions is therefore testimony that God transcends the laws of logic.
\end{abstract}

\section{Introduction: Defining Omnipotence}

Attempting to define the term 'omnipotent' by referring to a common English dictionary may not seem too difficult. Why should it? You pick up a dictionary, search for the word and your enquiry should reveal something like, 'all-powerfulness', 'almighty', 'having unlimited power', etc. Such characterizations would, at least to some extent, cognitively satisfy the layperson (that is, of course, if such a person is not seeking anything beyond the vernacular). The dictionary, in this context, would have succeeded in expressing a given meaning. It would have revealed a fairly common-albeit

Abbas Ahsan is a doctoral researcher at the John Hick Centre for Philosophy of Religion, situated at the University of Birmingham (UK). His current research focuses on the methodology and the possible application of analytic philosophy in the Islamic tradition.

Ahsan, Abbas. 2020. “God Beyond the Boundary-Stones of Thought." American Journal of Islam and Society 37, nos. 3-4: 50-97 • doi: 10.35632/ajis.v37i3-4.593

Copyright (c) 2020 International Institute of Islamic Thought 
an un-philosophical or philosophically superficial-definition of the term which the inquirer had been seeking. This seems fine-at least in isolation from any associated matters. It is only when we begin to associate the term 'omnipotent' with a god when the issue becomes apparent.

Many theists maintain that divine omnipotence is an essential attribute of God. Believing that God is all-powerful would have to imply that $\mathrm{He}$ is capable of doing all things. On the face of it, this would exclude any and all exceptions. On such grounds, God would possess absolute power and will, allowing Him to do everything that He so chooses. However, this hardly settles the matter. What exactly would it mean for God to possess such comprehensive power? What would possessing such power comprise and entail (that is, for God to have the ability and will to perform anything at all)? If there are no conceived limits to God's power and will, would it imply that He is able to carry out tasks that are casually, logically, and conceptually impossible? Would God, if He chose to, be able to change the past, or create a stone so large that He could not lift, or square the circle? The answers to such questions do not appear to lie within the definition of the term 'omnipotence' itself-at least not if you subscribe to semantic internalism. On the contrary, even if one were to subscribe to a semantic externalism, the matter would be far from being resolved. In the latter case, the manner in which the putative meaning of a given term is conceptualized and applied to that which it denotes would be prone to oscillating between degrees of vagueness in virtue of the agent. With respect to both semantic internalism and externalism, the definition of 'omnipotence' can be considered in one of two ways. It will either mean:

That God possesses maximal power relative to all his creation. This particular concept would not allow God to perform any state of affairs, but only those which are (logically) possible (i.e. conceivable). Determining such states of affairs would be subject to the agent (mind-dependent); or,

That God literally possesses the power to bring about and perform absolutely any state of affairs whatsoever; this includes necessary and impossible (i.e. inconceivable) states of affairs also. Determining such states of affairs would not be subject to the agent (mind-independent).

The former view represents the term 'omnipotence' to be relative to minds that are cognisant of the very term. In the case of God, His omnipotence is proportionally determinable in virtue of His creation. This position does not allow God do perform or bring about absolutely any 
state of affairs. It broadly restrains God to a cognitivist understanding of religious language. This in turn makes God susceptible to a whole host of philosophical categories, such as grammar, definability, existence, matters of fact, explanatory hypothesis, inferences, probability, conceivability, etc. An overarching category which God would be susceptible to and confined by, in this respect, would include the laws of logic. Consequently, He would be unable to perform any logically impossible and/or inconceivable acts.

The latter view refers to God's power in an absolute sense; one which is not relative to anything. This would also include that He has the ability to do the logically impossible, i.e. carry out contradictory actions. In early modern (Western) philosophy this understanding is attributed to René Descartes, the French philosopher, mathematician, and scientist. In a series of letters ${ }^{1}$ (around eight) to various individuals, Descartes implied that God is the creator of eternal truths and is able to perform anything whatsoever. For Descartes, it did not matter whether such acts are contradictory and therefore inconceivable for human minds to comprehend. God simply has the ability to perform them. Interpretations of Descartes suggestions infer that he did not hesitate to believe that God's power was one without any limit. Since God created all the eternal truths, they (along with all other necessary truths) are actually contingent. Thus, God could alter them how and when He willed in whichever manner He willed to do so. ${ }^{2}$ This includes God's ability to perform actions that would defy the laws of logic. Of course, there have been many objections to this view, since it entails an outright rejection of the law of non-contradiction.

The law of non-contradiction is formally expressed as $\neg(\alpha \wedge \neg \alpha)$ : namely, it cannot be the case that both $\alpha$ and not- $\alpha$. Regardless of the actual truth value of the variable $\alpha$, according to this law, the formula on the whole would always be true. This is because a statement and its negation cannot both be true at any one time. The truth of this matter holds no matter what the actual facts of the world may be. This kind of truth is commonly known as a tautology. Likewise, a contradiction (the result of defying the law of non-contradiction) would always be false no matter what the actual facts of the world may be. Adhering to the law of non-contradiction would therefore impose a genuine constraint on the way in which one conceives the structure of reality. ${ }^{3}$ The law of non-contradiction prohibits one from accepting/asserting the existence of a contradictory matter or state of affairs, subsequently barring one from accepting/asserting its truth. ${ }^{4}$ On this view, God cannot bring about a state of affairs that is contradictory. Doing 
so would not only be a rejection of the law of non-contradiction but would present a distorted view of our conception of reality or reality itself.

When the issue is presented like this, namely, in a logical context, it becomes hard-hitting. From this perspective accepting or rejecting the law of non-contradiction would dictate as to whether we conceive of a consistent or inconsistent view of reality and God's ability, respectively. This is certainly the case if the law of non-contradiction is considered to be self-evidently true, irrespective of what one thinks and how the facts of the world might turn out to be. However, Descartes seems to be drawing our attention towards something very different. For Descartes, eternal truths (which may be inclusive of arithmetic and the laws of logic) do not entirely enjoy a mind-independent status. Truths of this nature are not to be considered in the way they commonly are.

It is God, according to Descartes, who has created all the eternal truths. His power is of the kind which allows Him to do so. His ability and will to create such truths implies that He transcends them. This means that God is neither confined nor compelled to act in accordance with such truths. If God happens to create a contradictory state of affairs and we fail to conceive of such states of affairs, then our inability to do so would be a manifestation of our conceptual limitations-not God's. Our conceptual inability does not restrain God's omnipotence in being able to perform those very actions. ${ }^{5}$ Descartes is supposing that God cannot have any limits. He is infinite. Moreover, this would imply that the finite human mind would fail in conceiving of this God in His entirety. Brink writes,

Therefore, Frankfurt has seen, it is a mistake to seek a logically coherent explication of Descartes' assertions on God's ability to make contradictions true or change the eternal truths. For this would mean to try to comprehend the incomprehensible, which is not only impossible and unnecessary, but even impious. (Brink 1993, 8)

In light of the above it appears that much of the controversy surrounding the concept of omnipotence, or more specifically adopting a specific explanation of omnipotence, needs to be distinguished as to whether it can be attributed to God in its full sense or not. For if you maintain that omnipotence is maximal power, but yet still constrained by logical possibility, then it would entail that the definition of maximal power is rather one of limited power. This line of thought would appear to be somewhat unfitting to the nature of a traditional omnipotent God. Alternatively, if you uphold the idea that omnipotence is maximal power, which is not constrained by 
logical possibility, then this would result in absolute power. We can then categorize these into the following two notions:

God is conceivable in His true state and so are His actions. This would make Him finite on the grounds that we, His creation, would be capable of conceiving of Him. Consequently, He would not be able to perform all tasks whatsoever, because whatever is conceivable to us must be a logical possibility. Otherwise, logically impossible acts are rendered inconceivable to us; or,

God is inconceivable in His true state and so are His actions. This would make Him infinite and absolute. He would transcend the conceptual ability of His creation. Consequently, He would be able to perform all tasks, logically impossible or not. We would not be able to conceive or apprehend Him or His actions in any delimited sense.

I will argue the latter point in the course of this paper. I shall demonstrate that God is omnipotent in the sense that $\mathrm{He}$ is able to perform all acts regardless of whether we are able to conceive of them or not. The failure of our capabilities in conceiving of those acts does not imply that they are 'impossible' in themselves as states of affairs but only to the confines of our human reasoning. Thus, the implications of a logically impossible act would not be inherently impossible for God. Instead, its concept and linguistic association to our intellect fails to correspond with any analogous thought process or states of affairs in the actual world.

In particular, I will present why it is that we fail to conceive and apprehend logically impossible states of affairs. This would in turn reveal that since we are constrained to certain laws of logic, we cannot infer particular truths as 'absolute' and 'necessary'. Inferring that certain truths are absolute and necessary would require us to apprehend the true nature of absoluteness and necessity (in their entirety). However, we cannot do so. This is because the human mind is finite and incapable of generating any original thought. Thoughts cannot exclusively be dissociated from human experiences. It is the complex association between our thoughts and experiences that contribute to what have become commonly known as the boundary stones of thought. This would include our thoughts about what have been termed 'absolute' and 'necessary' truths. I shall argue that they too are relative to human thought. In extension of this claim, I shall infer that all human knowledge is relative. So when we make the claim that 'God cannot do the logically impossible', then that claim too is relative to variations in 
reference frames and conceptual schemas. It would not, therefore, make it 'impossible' for God to perform all acts, as $\mathrm{He}$ is an infinite and absolute being. Instead, such matters would contribute to exhibiting our very own limited mental capacities.

I do not anticipate elaborating on the very notion of God Himself from a theological perspective. Nor do I associate the God in question to any one of the monotheistic religions. The reason for this is twofold. First, this is a philosophical study which predominantly focuses on epistemic and metaphysical matters to do with logical laws and the boundaries of thought. It anticipates applying the findings of this study to a particular theological problem that is to do with God's omnipotence. It does not engage with theological discourse beyond the point related to the problem of God's omnipotence. Some may consider this an inadequate way to address such a theological problem, while others may deem it theologically irrelevant and/or redundant. I think the charge of theological inadequacy and irrelevance seems to be slightly misplaced in a philosophical study such as this one. That is, of course, not to overlook the theological end to which such a philosophical approach is being applied. Moreover, a serious theologian would acknowledge the significance of contemporary modes of philosophical thought. For some theologians philosophical thought may even take precedence over matters of theology. Theologians who fall into this camp hold that the manner in which philosophical thought is understood and subsequently applied to theological matters would contribute (and perhaps even shape) the kind of theology one engages in. Second, the notion of God that I have in mind, as well as the argument I hope to construct, is open to any one of the monotheistic religions to adopt. Although I make an indirect reference to the Islamic tradition in passing, I leave my argument open for members of the Christian and Jewish traditions to adopt if they so choose to do so.

I initiate my discussion by presenting and arguing for the notion of epistemic relativism. Subsequently, I apply the idea of epistemic relativism to various forms of truths in order demonstrate its viability. Thereafter, I apply the notion of epistemic relativism to the idea of God, or more precisely to the notion of omnipotence.

\section{Relativism}

Relativism in general argues that points of view have no absolute truth or validity. Instead, they only have relative and subjective value according to differences in perception and consideration. Prior to taking a closer look at 
this definition it is worth noting that there are two overlapping characterisations of what has been termed 'relativism'. These include the following:

Relativism about propositional truth: whether a proposition is true is not an absolute fact. Propositions can be true relative to some contexts of assessment, and false relative to others; and,

Relativism about utterance truth: whether an utterance is true is not an absolute fact. Utterances can be true relative to some contexts of assessment, and false relative to others. (Shirreff and Weatherson 2017, 789)

There is a subtle difference parting the two types of relativism; which one of these constitutes a proper form of relativism is disputable. It is not always apparent as to which one of these is being defended or refuted by authors. I suppose it is natural to think that those engaging with relativism are doing so with the first type (relativism about propositional truth) in mind. I too shall engage with this type, since it appears to be the kind which is relativism proper. Yet there may be instances where an overlap between the two types becomes unavoidable. Krausz, for instance, has presented a definition which appears to represent the former type. He suggests that,

Relativism claims that truth, goodness, or beauty, is relative to a reference frame, and no absolute overarching standards to adjudicate between competing reference frames exists. (Krausz 2010,13)

In regards to these 'reference frames', he further suggests,

Relativists hold that several incompatible non-converging reference frames, in terms of which we perceive and understand the world, could exist. At the boundaries of pertinent reference frames, where grounds for evaluation unique to those frames exhaust themselves, we have no absolutist way to adjudicate between contending frames. No absolute frame-neutral grounds for adjudicating between frames exist. For the relativist, where standards of evaluation are exhausted at the bounds of reference frames, the search for pertinent absolute standards makes no sense. (Krausz 2010, 14)

Not only does this suggest that we cannot have an absolute way of adjudicating between contending frames; it also implies that there exist no grounds for adjudication between frames at all. This would rule out or deny the possibility and acquisition of absolute standards of knowledge. Thus, the absolutists' worry becomes apparent where, if such is the case, then 
you would be inviting arbitrariness, anarchism, or nihilism. No worthwhile goal of inquiry would exist.

I shall return to such objections shortly. At present I shall focus on exactly what a 'reference frame' is, prior to investigating whether any grounds for adjudication exist. According to Krausz (2010), reference frames come in many varieties and their usage tends to vary upon the interests and purposes of individuals. The comprising elements range from concepts to situations, personal thoughts and ideas to cultural, religious, and historical perspectives. Occasionally we may not even be able to distinguish what a particular reference frame consists of (i.e. what content or constituting element it should include and what it should exclude). The boundaries are not clear-cut in any decisive manner. Consequently, each and every aspect of that particular reference frame cannot be easily categorized.

You may, for instance, have two traditions whose boundaries range from being significantly equivocal, to being partially imprecise, to being difficult to delineate altogether. Moreover, the diversity of the issue seems to broaden when some people are relativists in respect to one aspect of a given tradition and not another. For instance, some may adopt a relativist view with respect to conceptual schemas yet not with respect to civilizations or individuals. These relativists are referred to as 'local', as they conform to only some reference frames. On the other hand, those who apply a relativist view to all reference frames are referred to as 'global'. The above-mentioned elements which constitute reference frames are neither exhaustive nor exclusive. Rather they can depend on the individual's experiences, which may significantly vary.

Some relativists who seek to arbitrate and conform to a method of adjudication may resort to a significantly modified view of Kant $(1996,2007)$. The implication from the latter view is that whatever we experience, it takes on form in virtue of certain reference frames. This suggests that the diverse apprehension and understanding of the many variations of reference frames is a result of the experiences we accumulate in the course of our lives. Kant further emphasizes that the mind arranges and enforces concepts on sensory data which determine the form taken by our experiences of the world. Basic concepts are provided by the mind with which it organizes and interprets experience. The mind does not merely receive information; it actively organizes it to make sense of this information. Consequently, the world as we conceive it represents an order that the mind constructs. This process encapsulates all spatial, temporal, and causal orders which are 
manifestations of the logical procedure of all possible forms of judgment. However, despite Kant's understanding of how we conceive and make sense of our experiences of the world, he discards the relativists' claim that the content of experience is relative to numerous and possible forms of reference frames. For Kant, although experiences give rise to various reference frames, it is not relative to those variations. This is because Kant thinks that the logical structure of all possible forms of judgement is basic and unique in the sense that it rejects diversity. Thus, necessary and universal conditions for the possibility of experience exist, because for Kant,

although all our knowledge begins with experience, it does not follow that it arises from experience. [He further suggests] ... there really exist in our knowledge such necessary and in the strictest sense universal, and therefore pure, a priori judgments. (Kant 2007, 37-39)

The apprehensions of worldly experience which we encounter are invariably mediated through 'forms of intuition' or 'categories'. These, for Kant, are the necessary elements of all knowledge. In the absence of these a priori categories, Kant suggests that encountering an experience of the world itself would be impossible.

If this is the case, then it should follow that there must exist some method of adjudication between reference frames. That is, even if these $a$ priori categories do determine the fact of actually encountering an experience of the world, as Kant puts it, there still, in this case, needs to be some decisive factor which acts as an adjudicating element. However, there just doesn't seem to be one! The mind, for Kant, plays a crucial role in determining how we actually perceive reality. In absence of the mind we really cannot know what is out there. Nonetheless, the essential question is not how or what role the mind actually plays in perceiving reality or shaping experiences in a way that allows us to make sense of the world. Instead it is whether there is a fixed and decisive way in which we come to perceive reality in the way we do. Is there an adjudicating method which our mind refers to when making sense of the world in the way it does? Thus, the dispute with Kant is not how (in a descriptive sense) the experiences we encounter are actually perceived. Rather, it is how (in a prescriptive sense of a fixed method) an indeterminate process of selecting our (certain) experiences gives rise to absolute truths.

Krausz expresses his contention with Kant's view by suggesting thatalthough it may provide us with some idea of how we conceive of our experiences-it does not dissolve the relativist's fundamental issue. That 
is, Kant's view fails in offering a decisive method of adjudicating between reference frames. Krausz writes,

even if Kant is right that the structure of the world as we experience it is imported into that experienced world by our perceptual and cognitive resources, we would still not have the resources necessary to adjudicate between reference frames. All that Kant's resources would provide are the conditions necessary for us to experience the world at all. While Kant's categories may be necessary and universal for the possibility of experiencing objects as objects that they come to be, it does not follow that those categories determine the characteristics that individuate them or the conditions that adjudicate between admissible and inadmissible objects of knowledge. (Krausz 2010, 19)

Nonetheless, Kant's position would not deter the relativist from their view that no absolute standards of knowledge exist. This is simply because there exist no grounds for adjudication between reference frames. How then might one gauge or determine with any degree of certainty the validity of any proposition? What elementary factors would fundamentally influence such thought processes?

The causes for this diversity in the patterns of thought rest on variations in concepts (granted differences in language, historical milieu, culture, economic status, etc.). The possible patterns of thought of an individual who makes any given judgment would depend on that very individual's 'conceptual schema'. This involves the cognitive elements of concepts such as beliefs, laws of logic, etc. Davidson expresses the role of conceptual schemas as

ways of organising experience; they are systems of categories that give form to the data of sensation; they are points of view from which individuals, cultures, or periods survey the passing scene. (Davidson 2010, 140)

If our 'cognitive procedures' (i.e., modes of thought) rely on available and accessible cognitive resources, then to say that truth is relative to patterns of thought would be to say that truth is relative to conceptual schemas. Runzo has emphasized the same point by asserting that

thought and patterns of thought are only possible in virtue of a background context of presuppositions and assumed concepts. There is no such thing as a (literally) utterly isolated thought. A thought is a thought in the context of other possible thoughts, and of the cognitive resources which make those thoughts possible. (Runzo 1986, 35) 
However, why might one suppose that truth is relative to conceptual schemas? What reasons would a relativist propose to substantiate such a position? The fundamental idea rests on the presupposition that there is not a singular set of facts about the world (in contrast to William James). James (see Runzo 1986) suggests that if there are true ideas (i.e., which correspond to reality), then there must only be one set of facts about the world. Irrespective of what is thought to be true by people who happen to think about things differently, "facts about the world" are immutable. From this perspective you shall have some people who uphold true knowledge (in which facts actually correspond to reality), and others who uphold false knowledge (in which facts fail to correspond to reality). It is this success and failure to correspond to reality which, for James, is the determining factor by which we are able to obtain decisive facts about the world.

Opposing James' view, a relativist would either have to reject the idea that there is a corresponding relationship between matters of fact and the world (or reality), or that there is only one way the world is. Let us focus on the latter of these. The relativist would have to provide evidence that there is not a singular set of facts about the world. Let us first ascertain two underlying assumptions upon which this claim would rest:

That there exist no neutral facts about the world to which we have access. Additionally, similar to what Kant proposed, there are no facts which are completely autonomous of minds, even though they may be discovered by minds. In other words, facts are not just simply read off from the world which we perceive and experience, but instead, the world to some extent constitutes the facts as we read them in virtue of our schemas; or

That the mind can create more than one adequate construction of the facts about the world. This assumption asserts that while facts are, in part, a construction of the mind, there is no correct or decisive manner in which the mind should actively impose this constructive element. Consequently, there is no single correct manner that the facts about the world should actually be.

The above assumptions are indicative of at least two matters which are responsible for determining our view of reality. Firstly, the possible constituting elements of reality are not merely determined by how the world actually projects itself onto its observer (call this the external factor). Instead this needs to be coupled with the manner in which the recipient goes on to perceive the world in virtue of their conceptual scheme (call this the 
internal factor). One factor cannot be entirely discounted at the cost of the other. This begs a question, bringing us to the second matter. How do our minds (advertently or inadvertently) adjudicate between external and internal factors in a manner that draws the required balance, allowing for us to make sense of reality? That is, if both the external and internal factors are integral in contributing to what we may refer to as perceptive and even conceptual knowledge, then such contributions must in some way be processed in arriving at that knowledge. This means our minds must undergo some process in virtue of which we able to arrive at consistent views of reality which ultimately gives rise to such modes of knowledge.

Davidson (2010) argues that the whole idea of conceptual schemas is incoherent. The issue rather is one of translation, as he suggests that the initiative for understanding the thought of others is equivalent to the initiative of finding our own words for those thoughts or, in other words, translating the words of others into our own. That is, we can (to some extent) articulate in our own words what others think. What Davidson is making apparent here is a linguistic diversity which demonstrates and echoes significant dissimilarities in style and value (although differences in points of view would not make any sense if there is no common coordinating system onto which to plot them). He therefore proposes that we require some considerations that would fix the parameters in order to conceptually contrast one view from another. Davidson insists that we need to be able to decisively refer to some set of adjudicating laws. More importantly, such laws are required to authenticate our judgement or knowledge.

Davidson moves on to suggest that conceptual schemas may be identified with languages - or rather, a set of languages - which express the same schema. Thus as conceptual schemas differ, so do languages. (Granted, speakers of different languages may share similar or even identical conceptual schemas.) This would imply that studying the art and criteria of translating languages is a way of understanding the criteria of identity for conceptual schemas. Nevertheless, he asks, could we say two people have different conceptual schemas if they speak languages which fail to be translated to one another? In reply he states,

In what follows, I consider two kinds of case that might be expected to arise: complete, and partial, failures of translatability. There would be complete failure if no significant range of sentences in one language could be translated into one another; there would be partial failure if 
some range could be translated and some range could not. (Davidson 2010, 142)

In regard to the case of complete failure, he writes that,

nothing, it may be said, could count as evidence that some form of activity could not be interpreted in our language that was not at the same time evidence that that form of activity was not speech behaviour. (Davidson 2010, 142)

So for Davidson, if one language has the capability of entirely being translated into another, then no real differences of conceptual schemas can lie behind those languages. On the other hand, if one language cannot be fully translated into another, then in such a case a substantive difference of conceptual schemas would be implied.

Blackburn (2010) quite rightly refers to this position as a kind of "linguistic imperialism", by which anything said in late-twentieth-century American terms should not make sense whatsoever (simply because speakers of the same language can possess radically different conceptual schemas). Consider an English-speaking, late-twentieth-century American astrophysicist who expresses a phrase or a term which may not be entirely understood to an English-speaking, late-twentieth-century American astrologist. Alternatively, consider those possessing the same conceptual schema who happen to speak quite different languages in order to express those schemas. The disparity in both cases impedes the sort of correspondence that is sought and seen as necessary in order to communicate.

Blackburn further highlights the concern of implicit verificationism: the somewhat unpopular philosophical concept which asserts that the possibilities we are unable to verify as obtaining, cannot qualify as real possibilities at all. A more concerning feature of this type of verificationism arises when we are required to translate unverifiable content with the aid of our language. In such cases the manner in which we obtain some adequation of the content of our minds would hinge (although not entirely) on how satisfactorily we are able to linguistically represent that content.

For if we consider the enterprise of learning we realize that the art of learning is not merely an act of translating. Take for instance a student who would like to verify whether the content taught by the instructor actually makes sense. Making sense of the content would not only include translating it into a mediatory language or expressing it in alternative modes. Instead, this profound undertaking involves expanding and changing 
conceptual repertoires. Discovering new vocabularies, concepts, and theories and expanding different avenues of understanding various phenomena all contribute towards making sense of what is taught. An exclusive focus on translation would fail to provide meaningful context in being able to make sense of taught and/or acquired knowledge.

Davidson presents an argument which attempts to undermine each metaphor of this equation. He writes against the idea of a scheme 'organizing' experience; quite reasonably, he notes that it is only "pluralities" which get organised. If, for instance, you were tasked to organize smaller sets of shoes and shirts in the absence of a larger set, say a closet, then such a task would be somewhat bewildering. Of course, Davidson does not mean to imply that such a trivial task would be made impossible in the absence of a closet. Rather his analogy seeks to draw our attention to the point that although some languages may contain terms that are not equivalent across other languages, there exists certain features that are common between them. It is the existence of such common features that creates for the possibility to determine and decipher identity claims. Despite the fact that you and I may have our own differing ways of strategically and aesthetically organizing the same closet, there exists a common feature making each of us alike in some way, namely, dealing with sets of shoes and shirts. Similarly, although you and I may be using different languages to imply the same thing, we in turn would be dealing with the same set of conceptual definitions.

In reply to Davidson, Blackburn says (while attacking the notion of 'fitting experience'),

Davidson seems to detach language too far from the detailed, piecemeal procedures of verification that are part and parcel of our lives. He is eventually left with the unconvincing substitute of covering our beliefs with a snowy mantle of truth, leaving their particular and individual footing in experience of no importance (hence the claim to have destroyed any final allure of empiricism). (Blackburn 2010, 167-168)

Blackburn's reason for making the above claim is based on the assumption that we need not associate the conceptual schemas with the 'organize' metaphor. This is because shifts in language and theory do not actually play a part in altering experience. Rather, it is experience that shapes experience. Take listening to a particular tune that is played using a musical instrument, for instance. You hear and experience a set of fixed notes being played in an arranged manner. Thereafter, you have (subconsciously) retained an 
experience of the set of notes played in this tune. Now suppose you hear the same set of notes being played by the same musical instrument for a second time. However, upon this occasion, the set of notes being played are arranged in a slightly altered manner. Consequently, you have retained an experience of a different pattern of notes played. As a result, you have experienced two different tunes composed by the same set of notes and using the same musical instrument. The only difference is that each of the sets of notes were played in different sequences. I could only recognize that a change existed after having heard and retained the experience of hearing at least one of them (irrespective of the order). At each and every instance my experience appears to be the determining factor in demarcating present experiences and previously retained ones. In such cases, change is not really determined or effected by shifts of language, concepts, or theories. Rather, it is a former experience which influences and shapes the latter. Thus experience seems to take precedence over our conceptual schemas in influencing our experiences.

But what is it, then, that makes experiences and utterances of a relativistic nature true? Davidson refers to our thoughts being drawn from a minimalist view of truth. This implies that nothing general or abstract can be said about truth. In other words, any given sentence, providing it locates a definite issue, can only be said to be true if it is translatable into my own language (i.e., by the terms which that sentence provides). You may come across a foreign sentence which you cannot translate, and as a result cannot determine its truth or validity; however, you can envisage a translation enabling you to identify the content of that sentence. That would inform you as to what would count as its truth (or truth-maker).

However, it is difficult to see how this line of thought yields a standardized truth which offers an association between two different minds. The problem is not with what the minimalist says-that no 'thing' makes sentences true, and furthermore that it is also true that I cannot say exactly what makes a foreign language true (or false, for that matter) unless I know what it means. Despite whatever certainty these two points carry, neither of them brings us any closer to rejecting the possibility of a significant disassociation between two separate minds. The cognitive processes involved in each would appear to be fixated onto different versions of how they perceive the world. It is these variations in perception which the account of conceptual schemas is attempting to demonstrate in theory. Discarding conceptual schemas would imply that some other sort of invariable theoretical 
framework subsists to which reference can be made for adjudicating and authenticating all experiences and utterances. As a matter of fact, this is precisely what the relativists deny. The relativists' idea can be represented in the following manner:

For all $X$-judgments, some feature, $F$, of an $X$-judgment is relative to $Y$

If that is actually the case, suggesting that all judgments (and/or truth) are relative, then the general objections would be those raised by Putnam and Rorty:

If all truth is relative, then the truth of the premises of this argument are only relative. and the conclusion is only true for someone who already holds it, or is inclined to hold it. Were this the case, the argument would be inconsequential; and

Second, it is plausible to suppose that there is more than one adequate way to conceive of what is possible, because of the impressive plurality of conceptual schemas, past and present, and the pragmatic success of so many actual schemas as well as the probable future success of a virtually limitless plethora of possible future schemas. Thus it seems most plausible to conclude that there are alternative, adequate sets of facts about the world. (Runzo 1986, 38)

The first objection emphasizes that relativism is incoherent or rather self-defeating: if it attempts to support its claim relatively, then it would simply beg the question; if it attempts to do so non-relatively, then it would require giving up the concept which it is theorizing. This objection can be represented in the form of the knowability paradox, which can be formalized as follows:

The Knowability Paradox: $\forall p(p \rightarrow \diamond K p) \vdash \forall p(p \rightarrow K p)$

If all truths are knowable in principle, then it logically follows that each truth is (at some point in time) known. A proposition stating an unknowable truth would also be knowable. To demonstrate the commonality between the knowability paradox and the objection against relativism as stated above, we can alter the $K$ (the epistemic operator) with $R$ to represent relativism. In such case we would have:

The Relativism Paradox $\forall p(p \rightarrow \diamond R p) \vdash \forall p(p \rightarrow R p)$ 
If all truths are relative in principle, then it logically follows that each truth is (at some point in time) relative. If all truths are relative in principle then there cannot be any un-relative truths. A proposition stating an un-relative truth would also be relative. The paradox is apparent.

In reply to this objection it would be helpful to acknowledge that an argument for relativism would amount to an argument against absolutism. Epistemically, absolutism asserts that there is (or exists) only one correct or authoritative fundamental standard (though possibly comprised of various constituting components) for assessing epistemic merit. It further concedes that this manner of assessment has not possibly been adopted by any person in its entirety. Thus, this standard seeks to determine epistemic appropriateness, not merely for beliefs but also the rules for adopting particular beliefs. However, it seems almost unavoidable that you shall eventually encounter two competing beliefs (or rules) which appear equally justified. If this is the case, then according to this authoritative standard you would simply have to suspend judgement. This would compel one to abandon the matter at hand whereby no likely resolve would be possible on rational grounds.

Relativism, however, supports contrasting views while denying epistemic absolutism altogether. Ironically, supporting contrasting views against the absolutist does not appear to place the relativist in any better position. For such views, irrespective of whether they are in support of relativism or in opposition to absolutism, would fail to be defensible for determined relativists. Conversely, supporting absolutism and opposing relativism would equally fail to be defensible positions for determined relativists. The charge an absolutist may advance against the relativist is that no absolute overriding adjudication standards actually exist. Consequently, there would be no worthwhile goal of inquiry. Moreover, it would diminish the possibility of progress in knowledge and force the relativist to resort to arbitrariness, anarchism, or nihilism. During this charge, the absolutist may firstly make it apparent that standards of adjudication do exist (for them at least) which the relativists fail to acknowledge. Secondly, they may take solace in their optimism toward and perseverance in seeking those standards. Thirdly, they may seek to demonstrate the possibility of advancing in knowledge during their pursuit of such standards of adjudication.

The relativist, on the other hand, would need to demonstrate that the absolutist's optimism is, below the surface, nothing more than an epistemic illusion; that it fails to deliver successful results. But how are the relativists 
to establish such a claim? There is a further issue which makes this demand more difficult to meet: any argument against the absolutist would imply that the relativist is committed to definite claims. At this point it would seem that the best a relativist could hope for in repudiating the absolutist claim is proposing that the absolutist's position is implausible. Such implausibility would be one that significantly rests on indeterminate optimism. That is the kind which appeals to hollow promises and a deep-rooted dissatisfaction in offering substantive adjudicating standards. However, this is far from an easy task. In fact, the likelihood that the relativist would fail the absolutist's challenge increases.

The relativist's frustration towards the absolutist, however, cannot be trivialized. One way to appreciate this is to consider the distinction between deflationist and inflationist accounts of truth. The deflationist account of truth is representative of an insubstantive truth theory, while the inflationist account of truth is representative of a substantive truth theory. I do not propose a strict analogy between deflationism/inflationism and relativism/ absolutism. Nonetheless, relativists may express their frustration about the absolutists by referring to notable features that distinguish deflationism from inflationism. More importantly, I hope to demonstrate that the relativists' frustration bears epistemic weight against the absolutists.

Sher presents five central elements of the deflationary theories of truth which are representative of the insubstantive account. These are central elements argued by Horwich:

1. Frustration with past attempts to develop substantive theories of truth;

2. Satisfaction with a trivial theory of truth;

3. Identification of the theory of truth with a single and simple definition schema;

4. Narrow conception of the role of truth in our cognitive life; and

5. Bold adequacy claim (Sher 2016, 819-820)

The first of these elements, quite frankly, manifests the deep-rooted dissatisfaction that the deflationists have mounted against the inflationists. This is primarily motived by the latter's ineptitude and failure to provide a substantive theory that captures the underlying essence of truth. The deflationists' frustration stems from the incompetency of the inflationists in providing satisfactory answers, which were thought to be subtle and profound, to fundamental questions surrounding truth. In fact, according to the deflationists the very pursuit of inquiring into the nature of truth has been exhausted. They have reached the limits of analysis to the extent that 
"hardly any progress has been made towards achieving the insight we seem to need" (quoting Horwich in Sher 2016, 820).

The second of these elements can be considered a consequence of the first. Given the inflationists' failure to provide a substantive account of truth, the deflationists' despair has led them to settle with a trivial account of truth. On this view, we needn't trouble ourselves with attempting to decipher the underlying essence of truth with the aid of profound philosophical investigation. Truth should be considered a vacuous (non-substantive) notion which does not require metaphysical grounding.

The third of these elements sheds further light on how the triviality of truth is captured. Being able to identify and capture truth instances for the deflationist is simple. The method is confined and neatly expressed by the equivalence schema: (ES) $\langle p\rangle$ is true if and only if $p$, which is logically expressed as: $T \leftrightarrow\langle p\rangle$. Trivial instances that are expressed by this schema are instances of deflationary truth. A common example is "it is true that snow is white if and only if snow is white."

The fourth of these elements expresses the domain in which deflationary truth bears value. Given that deflationary truth is metaphysically vacuous and therefore trivial, its value is exclusively logical. This means that the truth-value which the deflationist would arrive at would possess no more meaning than what the equivalence schema allows. Although this helps the deflationist arrive at a truth-value in a particular sense, it is one which would impede us from attaching any significant meaning to the truth-value in question. Nonetheless, for the deflationist this is hardly an issue. In fact, this very situation makes the concept of truth invaluable: "For it enables the construction of another proposition, intimately related to the one we can't identify, which is perfectly appropriate as the alternative object of our attitude" (quoting Horwich in Sher 2016, 820).

The fifth of these elements sums up the implication of the fourth element with a universal claim. "Referring to his own version of deflationism, 'minimalism,' Horwich says: [O] ur thesis is that it is possible to explain all the facts involving truth on the basis of the minimal theory. (Ibid.: 6-7, my italics) The entire conceptual and theoretical role of truth may be explained on this basis. (Ibid.: 5)" (Sher 2016, 820).

The deflationist then seems justified in expressing their frustration in the manner they have. Of course, I do not propose that the way in which this frustration has been expressed justifies the deflationists' position. I am making a more modest claim: that such expressions of frustration are not 
trivial, and cannot be ignored by the inflationist. Likewise, the relativists' objections are not trivial, and cannot be ignored by the absolutist. Nevertheless, the relativists still appear disadvantaged, though much of their objections have chastened the absolutist's confidence. Yet they are under no compulsion to meet the demands of the absolutist in substantiating their position. The burden of proof does not solely lie with them. Neither of these two positions, strictly speaking, has privilege over the other.

It is only when this balance is disrupted that we witness unwarranted demands. This is what happens when the absolutists demand evidence from the relativist. (If and when such demands fail to be met, then the relativist position is declared incoherent.) Even so, the relativists are required only to present their position, not to persuade the absolutists. It is unreasonable that a position only becomes coherent if one succeeds in satisfying one's opponent.

Krausz (2010) has referred to such a presentation of a position as offering "ampliative" rather than "determinative" reasons. Ampliative reasons are those rationales provided without seeking to convince others to adopt the same view, in contrast to determinative reasons. One might argue that the only reason for providing motives of such kind is to convince others. However, due to the fundamentally different frameworks which absolutism and relativism rest upon, it would be near impossible for proponents of either to adopt the other's views. Providing ampliative reasons to substantiate one's own position is sufficient.

However, if the relativists present reasons only good enough to support their own views, which do not on argumentative grounds correspond to any common substratum between them and their opponents, then these reasons would be exclusive to them alone. This would imply that relativism is a somewhat private or personal view rather than an idea which has rational (or empirical) evidence to substantiate its fundamental position and which could appear plausible to others. This would severely restrict the possibility of attaining universal consensus or acceptability. Nor should this consideration be limited to the relativist alone. We may accept and adopt a fundamental principle on inadequate grounds of rationale; if that is the case then many notions of thought which we preserve would be private or personal. Take religious beliefs, for instance. Various beliefs do not follow a strictly logical or rational form of thought. However, the absence of clear logical evidence or rational thought (or any form of evidence) does not eradicate or even diminish its credibility for individuals or groups. We 
presume that beliefs need be "justified", in the sense of presenting an argument to defend and substantiate them. However, Goldman quite interestingly proposes that,

I do not even assume that when a belief is justified there is something "possessed" by the believer which can be called "justification". I do assume that a justified belief gets its status of being justified from some processes or properties that make it justified. In short, there must be some justification-conferring processes or properties. But this does not imply that there must be an argument, or reason, or anything else, "possessed" at the time of belief by the believer. (Goldman 2008, 334)

Goldman suggests two points in the above passage. First, there exist some process or properties that make a belief justified. Second, justifying a belief would not necessarily mean presenting an argument or a set of reasoning, but rather would mean referring to some process or properties. The believer's belief would not need to convince his/her opponents but convince the believer him/herself in what he/she believes to be true and thus justified. We can present this in the following manner:

If $P$ believes $Q$ at $T$, and $Q$ is indubitable for $P$ at $T$, then $P$ 's belief in $Q$ at $T$ is justified

Again, we have arrived at some sort of personal and private way of thinking, one that does not have to conform with any particular ground rules in order to substantiate its position. We could correctly assume relativism to be in a similar position, not requiring an argument or a certain set of reasons to validate its position. In relation to this, Luper (2004) suggests that relativists making a case for relativism need not abide by the non-deadlock principle (i.e., that each side in a dispute must present their argument on the basis of assertions acceptable to the opposing side), whereas the absolutists must in fact abide by it. For the relativists intrinsically suppose that the non-deadlock principle is antithetical to their case, and discard anything that supports it. Therefore, accepting the non-deadlock principle would bar the absolutists from asserting that relativism is actually incoherent.

The second objection to relativism quite forcefully asserts that the plurality of views which relativism endorses would imply that either, amongst these views there is an absolute or definite way to conceive the world; or, (somehow) the plurality of views together in collaboration with one another would formulate one absolute or definite way to conceive the world. A common feature of both these views is that there exists, among all the 
alternative modes of thinking about the truth, a fixed set of facts about the world. As much as this objection may appear to be a decisive blow against the relativists, it simply misses the point of what relativism is proposing altogether. Relativism does not propose to offer a list of all the possible ways of conceiving the world. Neither does it seek out an absolute or definite criterion from among those possibilities for arriving at the actual truth. What this particular epistemic position infers is that the correctness of judgments about matters of truth would vary depending on those who are making the judgments. Since each and every individual's disposition and level of cognition varies, the knowledge perspectives I am exposed to and acquainted with (whether it be gender, class, sexuality, self-understanding, religious belief, aesthetic value, and so on) result in the alternative versions of truth I encounter. The more versions of truth I encounter-whether by stumbling across them in total coincidence or in advancing a strategic inquiry-the more my current position of truth would be challenged. Consequently, with there being many alternative versions of truth, there is no set criterion or method of adjudication between such truths that ultimately allows for an absolute truth.

\section{The Application of Relativism}

Thus far I have discussed what relativism proposes and how it manages to uphold its constituting features. I shall now like to discuss the application of relativism and the extent to which it can be applied to statements that are considered true. First, I shall clarify the 'statuses' of statements to which we apply a relativistic method. Runzo (1986) has categorized the statuses of statements into two groups, namely, first-order and second-order. ${ }^{6}$ This categorization is in a linguistic context and should not be confused with the logical context. He emphasizes that it is crucial to distinguish a relativist's conception of truth between these two types of statements. First-order statements are those used in an object language to refer to actual or possible states of affairs. For instance, statements like "today is $21^{\circ} \mathrm{C}$ " or "if I went to the moon..." are first-order statements. On the other hand, second-order statements are those about the object language rather than in the object language. These statements use a particular language in order to refer to and make statements (whether meta-logical or meta-linguistic) about formal properties of that language. For instance, asserting the law of non-contradiction (no proposition or statement can be both true and false at the same time) is a second-order statement of this type. 
In considering these two types of statements, it becomes clear that we can only apply a relativistic account to first-order statements, not to second-order statements. For example, if I stated that "today is $21^{\circ} \mathrm{C}$," then this statement from a relativist's perspective would only be true depending on the context (i.e., the reference frames as well as the conceptual schemas) in which it is perceived. According to the relativist this statement would not manage to present an absolute fact about the matter it aims to express. This is primarily due to the varying contexts in which it can be perceived. This much a relativist would be able to assert.

However, the case with second-order statements is very different. To demonstrate, let us take the example mentioned above (the law of non-contradiction). If such a law is also subjected to a relativistic account, it would compromise the very criteria that constitute relativism. This would include jeopardizing features such as reference frames and conceptual schemas, and would ultimately risk undermining the relativist's own position. Runzo refers to those relativists who are bold enough to apply their account to second-order statements as 'epistemic relativists':

I will use 'epistemic relativism' to refer to any position about second-order statements which holds or implies that the correctness or incorrectness of judgements about the nature of, or the criteria for, truth or for semantic meaning or for how knowledge is acquired varies with who is making the judgment. (Runzo 1983, 40)

In what follows he further suggests that if the authenticity or correctness of any view is itself relative to one's own schema, then in consequence, deducing a criterion which aids in successfully building a theory of truth, or defining terms by giving them a meaning, or more generally the acquisition of knowledge, would be futile. It's not surprising to encounter such futile consequences since epistemic relativism seems to clearly abandon all types of fundamental criteria. If such a position "liberates" itself from all adjudicating criteria it would then bring us back to the arguments previously leveled against relativism, namely, that this line of thought would seem to defeat the whole purpose of having a theory about the nature of truth. So, this form of relativism is abandoned not only because it makes incoherent claims but also because it simply fails to deliver a theory of truth.

Given such criteria, these severe consequences are apparent in the bold assertion that "all truth is relative", which intends to relate to every form of truth that may be accessible or known. They are even more explicit when considering modalities (that is, modal instances which are expressive 
of extensional terms such as possibility and necessity). We resort to these types of statements when we talk of states of affairs that could or must occur (within the domain of possibility and necessity, respectively). The occurrence or non-occurrence of such states could be determined in one of three ways: either in virtue of causal laws and how they (are perceived to) operate and impact the physical world; or in virtue of the laws of logic and how we may think about them; or, more fundamentally, in virtue of how we acquire the meanings of terms and the manner in which we use those terms to denote matters of the world. Here are some examples that fall into each of these categories, respectively:

\begin{tabular}{|l|l|l|l|l|l|}
\hline \multicolumn{2}{|l|}{ Causal } & \multicolumn{2}{l|}{ Logical } & \multicolumn{2}{l|}{ Conceptual } \\
\hline Possibility & Necessity & Possibility & Necessity & Possibility & Necessity \\
\hline Example: & Example: & Example: & Example: & Example: & Example: \\
'it is possible \\
to dissolve \\
$\begin{array}{l}\text { sodium } \\
\text { chloride in }\end{array}$ & $\begin{array}{l}\text { 'it is nec- } \\
\text { essary that } \\
\mathrm{H}^{2} \mathrm{O} \text { ' }\end{array}$ & $\begin{array}{l}\text { cathing } \\
\text { can travel } \\
\text { faster than } \\
\text { the speed of } \\
\text { thething }\end{array}$ & $\begin{array}{l}\text { ever existed } \\
\text { in the uni- } \\
\text { verse' }\end{array}$ & $\begin{array}{l}\text { 'it is nec- } \\
\text { essary that } \\
\text { every giraffe } \\
\text { is identical } \\
\text { to itself' }\end{array}$ & $\begin{array}{l}\text { 'it is possible } \\
\text { that some } \\
\text { animals } \\
\text { which we } \\
\text { refer to as } \\
\text { species of } \\
\text { birds are } \\
\text { essary that } \\
\text { if John is a } \\
\text { bachelor, } \\
\text { then he is an } \\
\text { unmarried } \\
\text { man' }\end{array}$ \\
\hline
\end{tabular}

For the sake of relevance let us consider logical and conceptual necessities and possibilities. In order to obtain a somewhat nuanced distinction between both of these categories it would be worth making mention of alternative terms used in the domains of semantics and epistemology. This is not only to make apparent the differences between them but to avoid confusing them with one another. Let me begin with the domain in which these terms largely concern us, namely, metaphysics. A necessary statement is a statement that is true in all possible worlds. This is represented in the language of modal logic as: $\square$ A. Necessary statements are contrasted with impossible statements. Impossible statements are false in all possible worlds. Contingent statements, on the other hand, are true in only some possible worlds. This is represented in the language of modal logic as: $\diamond \mathrm{A}$.

This is not to be confused with the distinction made between what is analytic and what is synthetic within the domain of semantics. Analytic is true in virtue of its meaning while synthetic is true in virtue of the way the world is. Likewise, these distinctions are not to be confused with what 
is a priori and what is a posteriori within the domain of epistemology. A priori are known to be true independent of experience while a posteriori are known to be true in virtue of experience. This leaves us with logical necessity and possibility. It is more than often agreed that logical necessity and possibility are grounded in metaphysical necessity and possibility. This means that if a statement is considered to be logically true then it is necessarily true and if it is logically false then it is necessarily false in the metaphysical sense.

In most cases then logical necessity is what determines metaphysical necessity. We could then say that although the universe could have turned out differently, there are some ways the universe could not have turned out at all. For instance, there are many possible worlds differing from one another; however, it cannot be the case that there is (or we could conceive of) a world in which $2+2=7$. It could not also be the case that you both do exist and do not exist in this (or any other) world. We refer to these types of truths as 'necessary truths', because they are necessary in every possible world and cannot be conceived of otherwise. On the other hand, we can say that a state of affairs is logically or conceptually possible, if there is some possible world in which it obtains (or actualizes). Take for instance the statement that "all giraffes have short necks in a possible world." This is logically and conceptually possible. It could very well be the case that all giraffes are short-necked in some world other than this one. The notion of logical possibility is broadly inclusive of conceptual, metaphysical, and causal possibilities. Therefore, if something is logically impossible it certainly cannot be conceptually, metaphysically, or causally possible.

Perhaps a useful way to illustrate the expanse of logical possibility is in virtue of what is called "logical space," a term drawn from Wittgenstein (though he never defined it). ${ }^{7}$ Aranyosi comments,

Wittgenstein, who introduced the phrase to philosophy in the Tractatus, never defines logical space, yet we get a clear and intuitive idea of what it is supposed to be, namely, the space of all possibilities. If that is true, then we are immediately pushed to explain what possibilities are and what it means to say that logical space is the space of all possibilities. Traditionally, it is propositions that are taken as bearers of the modal properties of possibility, necessity, impossibility and contingency, and these modal notions are in turn explained by appeal to truth at a possible world. Logical space, then, is, according to current orthodoxy, a space of possible worlds, and possibilities are propositions true at some possible 
world, hence, belonging to logical space. Impossibilities will be propositions that are not true at any possible world; hence, they are not in logical space. Contingencies will be propositions that are possible but false at some worlds. Necessities will be propositions that are true at all possible worlds. (Aranyosi 2013, 9)

Let us now return to epistemic relativism. In light of the modal machinery introduced above, epistemic relativism would have to concede that not all truth is relative. That is because epistemic relativism cannot evade logical space and compromise necessary truths while resorting to variations in conceptual schemas and reference frames. Suppose it did (or attempted to) compromise necessary truths in this manner; could it justify the absurdity it results in? Let us take a necessary truth, namely, the law of non-contradiction. In the formula $\neg(\alpha \wedge \neg \alpha)$, regardless of the actual truth value of the variable $\alpha$, the formula on whole would always be true, simply because a statement and its negation cannot both be true at any one time. Irrespective of all conditions, this law is a necessary truth which cannot be otherwise in all possible worlds. We may also say that this law is an absolute truth, for its truth obtains in virtue of the way in which it is conceived by every possible conceiver situated in every possible world.

The epistemic relativist may interject at this point by arguing that the law of non-contradiction is actually relative to conceptual schemas and reference frames, and thus not a necessary truth. This would imply that there are possible instances in which the law of non-contradiction can be rejected. But that's not all. Applying epistemic relativism to the law of non-contradiction would not only be rejecting what the law posits but would also be open to accepting truth-value gaps and gluts-kinds of indeterminate semantic values, if you like. This acceptance of truth-value gaps and gluts, which is usually associated with First Degree Entailment Logic (FDE), is where the epistemic relativist may find some hope. By being paracomplete and paraconsistent, FDE logic is able to entertain the maximum available truth-values in comparison to both classical and alternative sub-classical logics. ${ }^{8} \mathrm{~A}$ paracomplete theory is able to sustain some meaningful and declarative statements that are neither true nor false. Statements of this kind are referred to as 'gappy' since they fall into the gap between truth and falsity. A paraconsistent theory is able to sustain some meaningful and declarative statements that are both true and false. Statements of this kind are referred to as 'glutty' since they fall into the intersection of truth and falsity. Thus, the introduction of non-classical logic affords the epistemic relativist some hope of maintaining their position with 
respect to the law of non-contradiction. They are able to maintain their position while circumventing the charge of inconsistency and/or irrationality.

Of course, an attempt to salvage the consistency and rationality of epistemic relativism by appealing to a system of logic that is able to accommodate truth-value gaps and gluts sounds a little cheap. That is not to say that there is no case to be made for epistemic relativism under the guise of a paraconsistent logic, such as FDE logic. I think there is plausible scope for epistemic relativism to explore that route. Similarly, there is also plausible scope for epistemic relativism to explore logical nihilism in this regard. Logical nihilism can be presented in at least two ways, as Cotnoir has stated:

Logical Nihilism 1 There's no logical consequence relation that correctly represents natural language inference; formal logics are inadequate to capture informal inference.

Logical Nihilism 2 There are no logical constraints on natural language inference; there are always counterexamples to any purportedly valid forms. (Cotnoir 2018, 303)

He argues for and presents a plausible case for the second type of logical nihilism. A major proponent of that second type is Gillian Russell, whose argument is as follows:

To be a law of logic, a principle must hold in complete generality.

No principles hold in complete generality.

There are no laws of logic. (Russell 2018, 308)

My aim is not to reconstruct and represent Russell's or Cotnoir's arguments here. I mean simply to indicate that non-classical logic and/or logical nihilism may provide resources for the epistemic relativist to defend their position.

Aside from appeals to paraconsistent logic and/or logical nihilism, one of the reasons an epistemic relativist may present in maintaining his/ her position would be the possibility of variation in reference frames and conceptual schemas. According to epistemic relativists, necessary truths irrespective of their status are also subject to conceptual schemas and reference frames. But how would this argument make sense in defying the law of non-contradiction?

As mentioned above, necessary truths are particular matters of fact which cannot be conceived of otherwise. To put it differently, they are such 
truths that once they are acquired, it is impossible by any method of thought to conceive of their converse. The antithesis of the law of non-contradiction, for instance, would be a contradictory instance: a square circle, a four-sided triangle, a married bachelor, or two straight lines that enclose a space. We fail to conjure a mental representation of these contradictory instances, no matter how hard we try. Such failure may be a representation of the limits of our thought. Alternately, such limits may be a consequence of internal matters to do with how our brains are hard-wired, or a consequence of external matters like how we are socially nurtured. How we comply with the law of non-contradiction here becomes of paramount importance. Efforts to contravene this law, under our conventional systems of thought, amount to being illogical and/or irrational-and indeed are equated with rejecting thought altogether.

There is little doubt that the law of non-contradiction has been upheld as high orthodoxy throughout Western intellectual history, ${ }^{9}$ with a few notable exceptions. ${ }^{10}$ The same goes for the most part of Islamic intellectual history (see also Zolghadr 2019) ${ }^{11}$ Even today this attitude shapes the predominant mode of thought in the Anglosphere. Aristotle himself postulated a defence of the law of non-contradiction in book $\Gamma$ of the Metaphysics. Yet for Priest (2006), it is not clear what Aristotle's arguments are meant to establish, nor how, exactly, his postulated arguments establish a defence of the law of non-contradiction. Regardless of that specific issue, which Priest details in an interesting fashion, the history of logic does beg the question of its grounds. That is to ask, what is the basis of these laws' intuitive appeal?

Locke speaks of an intuition that grants man the logical capacity to exercise reason without knowing how to construct a syllogism (Locke 2015, Book IV, paper xvii, \$4). We can appreciate this intuition when considering a child who, despite having had no schooling in formal logic, has his/her first encounter with arbitrating in matters of syntactical consistency. Given that such a child has had at least some exposure to an environment which is indicative of deductive reasoning, he/she shall possess a "pre-theoretical but still developed sense of what follows from what" as Rumfitt (2015) puts it. It is this intuitive sense of deduction that instinctively grants an individual the aptitude to appreciate syntactical consistency. It acts as the pre-theoretical foundation against which one can, in the most generic sense, determine whether a given logical system is syntactically consistent. Rumfitt is thus persuaded that classical logic occupies a default status. Such logic is then codified by a set of foundational principles which conform to our "intuitive sense of deductions." ${ }^{2}$ The conformity between such principles and our "intuitive sense of deductions" allows us to acknowledge the kind 
of structure and form in virtue of which we are able to determine what follows from what, namely, syntactical consistency. Any attempt to obtain this type of consistency would entail conforming to the laws of logic, simply because defying the laws of logic would lead to syntactical inconsistency. Of course, whether this conformity is one which completely corresponds to our intuition or bears epistemological gaps is an interesting question. ${ }^{13}$ Nevertheless, the idea that there exists some association between the laws of logic and our intuition grants a significant status to the laws of logic. This status is particularly espoused by classical logic on the basis that the laws of logic are fundamental axioms in virtue of which it operates.

This begs a further question. Do the laws of logic actually possess a superior status over other laws? Let us take natural laws as an example. The law of universal gravitation, for instance, offers an explanation as to why every object attracts every other object with a force that, for any two objects, is directly proportional to the mass of each object and inversely proportional to the square of the distance between the two objects. This law would thus explain why a marble falls to the ground from any given height. Of course, the explanation offered would not account for some discrete form of essence of the marble which would ultimately be responsible for its downward movement. To put it in Kant's terms, the law would not propose to disclose a distinct realm of noumena which would reveal the inherent nature or inner reality of that marble. Although the law of gravity succeeds in positing a quantifiable gravitational force acting between all bodies, it does not explain exactly how the force propagates through space. This was precisely Newton's frustration with the law. He was unable to offer a satisfactory explanation as to how the force of gravity so pervasively transmits between bodies that were separated by space. (Of course, the force of attraction very much exists, albeit at a distance.)

The law of gravity mathematically accounts for the downward movement of the marble every time it is dropped. The explanation offered is empirically successful within what we might call a scientific remit. The law then is a generalization which offers an explanation as to why objects with any given mass are influenced by a downward force. In sum it proposes to express the way in which nature works. The laws of logic are similar in this respect; they are expressed by the calculi in a manner which offers a generalized view as to what ought to follow from what, namely, logical consequence. The laws of logic are formulated to account for and distinguish correct arguments from incorrect ones. Does this then mean to suggest that 
the laws of logic are equally empirical generalizations? In response to such a query, Peregrin states,

there are two ways in which the rules can be considered normative. First, they are normative in the sense that what they generalize are already rules. Their instances are correct arguments-they are correct not because we logicians proclaim them as correct, they are correct before any logical theory is in play; they are such because human linguistic practices are essentially rule-governed. Logic is thus supposed to pick up rules that already govern our reasoning, though in their natural form they are implicit, and it is only logical theory that makes them explicit.

Moreover, the laws of logic are normative also in the second sense, in that they can be used as standards of assessment and criticism of actual argumentation. This is because what we do when we articulate them is not only to bring their implicit predecessors into the open but rather also to "finalize," streamline, and extrapolate them to the regions where they were not really operative. This is what happens during the process of moving toward a reflective equilibrium.

Given this, we cannot really say that logic addresses a reality behind the surfaces of natural languages. It builds on some very general rules (proto-rules?) that are constitutive of our linguistic practices but employs its huge apparatus to transform these implicit rules into something clear, unambiguous, and potentially binding ...

In this sense, I think that the status of the laws of logic is similar to that of natural laws (despite all the other dissimilarities): they do not bring to light a hidden reality behind appearances but rather bring a system to the appearances (to "save" them, as the Ancients would put it). Of course, the system cannot be chosen deliberately, it must fit the appearances-but there is no reason to think that it was there, as such, all the time already before we established it. (Peregrin 2020, 7)

Peregrin makes an interesting case for how we should think of the laws of logic. Such considerations seem to demonstrate that these laws do not possess the realist privilege they are commonly granted. Nevertheless, I shall now like to look at what distinguishes the laws of nature from the laws of logic. The former demonstrate how the physical world operates by resorting to regular observations of natural phenomena. ${ }^{14}$ These 
are regularities in the workings of nature; take for instance the three laws formulated by Kepler after he discovered the regularities which governed planetary motions. Newton introduced the notion of gravitational force, which determines the movement of bodies under the system of forces exerted on them. Let us take a general regularity that is categorized as a law of nature, namely, planetary movement in elliptical orbits around the sun. Let us very simply conceive of this law in reverse or, more freely, otherwise: that planets don't revolve around the sun in ellipsis but rather in triangular motions. Although this may result in a physical impossibility, it is not a logical one. It is not at all difficult to conceive of the planets in our solar system orbiting the sun in a triangular motion. In contrast, I am not able to conceive of the reverse or negation of the laws of logic at all. So what exactly is the distinguishing factor which allows my mind to transgress the law of nature in any given state of affairs, but not the laws of logic?

We observe the laws of planetary motion as absolutely binding on the celestial bodies themselves. They would obtain regardless of whether man had discovered the science of astronomy and formulated these regular observations into symbolic formulae or not. It follows that although man has acquainted himself with the study of astronomy and managed to view the matters of fact with the aid of mathematical calculations, his experience of those laws are known to him solely by observation and therefore are totally independent of his knowledge about them. In other words, acquiring knowledge about these regularities does not influence them in any way whatsoever. However, this is not the case when it comes to the laws of logic. They seem to come into operation as soon as man begins to think. They are directly initiated and influenced by the one who engages in the process of thinking. Furthermore, they are unlike the laws of nature, which conform to physical phenomena, in conforming to conceptual matters and the manner in which the thinker thinks. If a law (as in the case of a natural law) is independent of a thinker's thought altogether, then its reversal can be conceived of; whereas if it is subject or bound to a thinking process, it cannot be conceived of otherwise. A similar criterion is deduced by Mansel, whereby he suggests that

A law which is not binding upon me as a thinker may at any time be reversed, without affecting my mode of observing the same agents under their new condition. And I have no difficulty in conceiving such a reversal as at any moment possible, because, antecedent to experience, I had no internal bias which required the recognition of the existing law 
rather than any other. I have only to discard an adventitious knowledge. (Mansel 2012, 90)

Probing why the laws of logic cannot be reversed or conceived of otherwise requires investigation into the nature of thought itself. This means leaving the province of logic or at least considering its interface with language. I might be rationally compelled to say something like my diary cannot have a black and white cover at the same-but the cognitive failure to comprehend such a case would not constrain me from linguistically affirming it. I am able to articulate a postulation of a possible contradiction, though I may not be able to conceive of it. This can be extended to other contradictory matters such as my ability to linguistically affirm the possibility of a square circle, a four-sided triangle, a married bachelor, two straight lines that enclose a space, and so on.

If it is the case that I have the capacity to express and articulate logically impossible states, although they are inconceivable to me, could I then go further and articulate an exclusively original thought (or statement)? That is, not the kind which is bound by a logical possibility or impossibility but one that is free from experience altogether? This would be inquiring whether my mind allows me to think independently of the laws of logic. Before answering this question it would be important to make a distinction between conception and imagination, as one may be under the impression that to contemplate an anomalous object or thought would be an original thought. In order to have a valid conception of a horse, for instance, I must:

a. Be acquainted with the various constituting features of the animal and their correct meanings in order to arrive at the definition of a horse; and

b. Be able to combine those constituting features in a representative manner to form a visualization in my mind in order to adequately conceive of it.

The combination of $a$ and $b$ forms a concept which not only lies in my mind but also corresponds to a reality or my previously acquired experience in some way.

Imagination, on the other hand, is possible without one of these two points $(a$ or $b)$. It can be said to be an arbitrary formulation of memories without conforming to any systematic method. For example, I at this moment in time have in my mind the notion of a centaur. My conception of a centaur is one where I envisage the upper body of a man biologically attached 
to the lower body of a horse. This method of thought has violated $b$, one of the two points which formulate a concept mentioned above. In this case I have combined two known meanings and what they denote in successfully envisaging a biological amalgamation of a human and a horse. Therefore, the process of imagining combines known meanings and what they denote in random ways that are devoid of any systematic process. Imaginations have no relation to objects that exist in the real world. In the centaur case, I already possess a concept of a man and also of a horse. I randomly take the meanings of these concepts and what they denote and arbitrarily combine them to formulate a thought. The resulting features which make up this thought fail to correspond to this creature as a whole in reality. At the most it remains a mythical creature that is an object of possible perception.

We thus come to understand that in order to formulate both conceptions and imaginal objects we fundamentally need to know the meanings of particular properties and objects. Both involve arranging properties and objects in certain ways. If the arrangement is systematic and corresponds to reality in some way, then it forms a concept. If the arrangement is random and fails to correspond to reality, then it forms an imaginal object. But what would allow us to apprehend such meanings? We need both objects of knowledge and a means of perceiving them, prior to formulating concepts/ imaginal objects. This is frequently described as requiring some kind of experience (irrespective of its comprehensiveness) of a particular property or object, which would elicit an initial cognitive reaction and subsequently give rise to a concept. This would mean that human thought, on the whole, is subject to one's experience.

Having arrived at this point, let us return to the question posed earlier. Is it possible to articulate an exclusively original thought, one which is unrestricted by logical possibility or impossibility? That is, is it possible to conceive of an original thought that is free from experience altogether? If the thought we refer to is only operative within the domain of possible experience, as established above in the discussion of conceptualization/imagination, then the answer appears to be negative. This statement may not suffice in presenting a comprehensive insight into the dynamic complexities of exactly how the mind actually operates, i.e. in the causal sense or the varying dispositional states we find ourselves in. Nevertheless, it seems sufficient enough to establish the finitude of the human mind and thought processes, in that it makes apparent the limited capacity it bears in a finite terrain of experiences. Mansel has also conceded the same point. He emphasizes how the human mind is restricted in its method of thought. He states that, 
Experience tells us what is, but not what must be... If by experience is meant all that is presented in any mode of intuition, matter and form included; and if the question is understood to mean, Can we contemplate in thought any object which has never been presented as an element in any mode of intuition? The answer must undoubtedly be given in the negative. (Mansel 2012, 245)

The term 'experience' must be taken in a broader meaning here: it is not confined to external sensory perception but is inclusive of both external and internal modes of human operation. It includes all that which the mind is conscious of from an inner and outer perspective (i.e., referring to the laws of logic as well as the phenomena of matter). In other words, all of knowledge itself is derived from experience. Therefore, we can say that there is no thought that can be generated in the mind which is totally independent of experience.

However, if experience is the exclusive source in virtue of which we acquire all of our knowledge, and our manner of perceiving these experiences significantly varies due to reference frames and conceptual schemas, then what would we make of intuitive knowledge or a priori statements? Are we to abandon them altogether? As I have previously discussed, if an epistemic relativist were to conform to a set of fixed principles (necessary truths) to arrive at absolute truths or statements, he/she would have to discard his/ her own fundamental principles. That position would no longer be strictly relativist. The epistemic relativist thus appears to be in a dilemma between preserving their relativist account or discarding it altogether.

Although we have already dealt with this objection when discussing first and second order statements, I wish to present a supplementary argument to strengthen the case for the epistemic relativist. This time I shall refer to previously mentioned terms that lie within the domains of semantics and epistemology. Let us begin by identifying the distinction between Kant's analytic and synthetic a priori judgments:

Analytic judgements are those which contain nothing in the predicate but what has already been implied in the subject. For example, "all husbands are men" or "all bodies are extended." These are second-order statements.

Synthetic judgments are those in which the predicate contributes to the subject what is not already entailed therein. For example, to take Kant's own examples, "all bodies are heavy" or "all bachelors are happy." These are first-order statements. 
There is much controversy as to whether logical inferences are analytic and a priori. In spite of this controversy let us consider the law of non-contradiction to be analytic and a priori. This is the view of those who are exceptionalists about logic. In this case the law of non-contradiction would be, what we might call, a self-evident truth. One way to consider what a self-evident truth amounts to, is to compare it with the definition of an argument. ${ }^{15}$ The common way to think of an argument is that it is a combination of a conclusion (a proposition) and reasons (premises) to support that conclusion. Carefully considering such arguments, we realize that there can be conclusions that stand completely on their own, independent of any reasons to support them. This would be the case when nothing contravenes the conclusion and therefore it can be upheld without any reasons. This sort of conclusion is referred to as a self-evident truth.

The law of non-contradiction has long been deemed such a self-evident truth. More specifically, it is considered a kind of truth which has no opposing reasons to reject it or even call it into question. This means everything supports it while nothing contradicts it. Modus Ponens and Modus Tollens are clear examples of this. The validity of such argument-forms serve as basic inferential rules that are representative of the fundamental laws of logic. The validity of both these argument-forms are just as fundamental as the laws of logic that they stand for. Moreover, if the conditional premises that make up the forms of these arguments are true, then their conclusion cannot be otherwise. Given that the forms of these arguments are clear representations of the laws of logic, their validity is certain. This qualifies the law of non-contradiction and the law of excluded middle as self-evident truths that must always be true and cannot be false.

Given this, the epistemic relativist would say, if man is bound to such necessary and self-evident truths such as the law of non-contradiction, then surely it must be the case that the necessity of such truths along with their validity can be determined in virtue of themselves (without referring to external premises). But would that even be possible? Any attempt to determine the truth of such matters would compel us to transcend the very limits sanctioned by that law we are trying to affirm. It is, as Wittgenstein aptly put it, "in order to draw a limit to thinking we should have to be able to think both sides of this limit (we should therefore have to be able to think what cannot be thought)" (Morris 2008, 352). This would imply that man has the cognitive capacity and the intellectual means to apprehend a knowledge which transcends the absolute itself. The very fact that one can 
infer that something is absolute or necessary in-and-of-itself would indicate the capability to exceed the boundaries of that absoluteness or necessity (in that one would have to be able to discern whether or not something meets that standard of absoluteness and necessity). However, this is impossible because whatever is presented in "intuition" and represented in thought is nothing more than finite. Allow me to cite Mansel once more:

So long as the relation between subject and object exists in consciousness, so long each must limit the other. The subject is distinct from the object, and the object from the subject, and neither can be the universe. Nay, the object itself can only exist, as such, under the conditions of limitation and difference: it can be discerned only as one out of many; as implying the existence of other things besides itself; and hence, again, as a finite portion of the universe. The infinite cannot be an object of human consciousness at all; and it appears to be so only by mistaking the negation of consciousness for consciousness itself. (Mansel 2012, 247)

The 'infinite' then is a term we employ in language which expresses the negation of human thought, or rather makes explicit its limitations. It is much like referring to something as 'inconceivable'. This does not mean that that which is infinite and inconceivable to us is indeed non-existent. To assert that something is infinite and inconceivable is in actual fact to make apparent the limits of our thought. Such assertions would not be matters of fact about the external world but affirmations of the limits of our cognitive capacity. This does not eradicate the possibility for the inconceivable to actually exist. It could be said that terms such as 'absolute' and 'necessary' are inconceivable in themselves. They are inadequate in providing what are actual absolute and necessary truths. Furthermore, the "truths" they infer would only be relative to human thought (derived from experience).

Synthetic statements and judgments, on the other hand, require more than the concept which stands as the subject. Such statements and judgments add to our knowledge in some way. It is said that all empirical statements are synthetic. These types of a priori judgements actually do not trouble the epistemic relativist at all; as we have discussed above, such judgments would be referred to as first-order statements in which relativism can be applied. Nevertheless, to substantiate the relativist's position further, if synthetic judgements are based on empirical data, then they simply cannot represent absolute or necessary truths of any kind. This is because, if any statement is arrived at by observation (however regular or precise), it could be argued that 
1. The observer who makes the observation is subject to conceptual schemas. Thus, his/her observation would be relative to variations in reference frames and conceptual schemas.

2. The problem of induction, as famously highlighted by Popper (1963), who emphasized that such a dogmatic belief in science is explicitly predisposed to a psychological propensity instead of a rational one. Popper found the method of induction to be inadequate as a justification for scientific knowledge.

3. Lastly, although an empirical law may state for example the alterations of night and day, it does not by any means assert more than an invariable regularity which has been observed to take place. By affirming the observational fact that the earth rotates on its axis once every twenty-four hours and thus we witness the alteration of night and day, it does not imply that my belief in such a continuing and regular motion of observed order or natural phenomenon would be explained to me by these observations alone. It may be some constitution of various thoughts which gives rise to such a belief, or some law of thought which my mental cognition is compelled to abide by. Therefore, following this line of thought would mean the law in question is of mind rather than of matter.

Hence, the epistemic relativist would succeed in establishing that observational or empirical modes of data are subject to personalized experiences (i.e., relative to reference frames and conceptual schemas). The epistemic relativists would then conclude by asserting that our experiences are in essence the exclusive source of acquiring knowledge. As we have demonstrated that all experiences and truth are relative, then so must be the case with our knowledge. More importantly, it must be conceded that there exist laws of logic to which our minds are strictly compelled in conforming to all circumstances. After all, we have no alternative method of thought to resort to. Even if (hypothetically speaking) an alternative method does exist, we do not possess the cognitive capacity to embrace such a method of thought, since it would mean transcending the current laws of logic to do so. It would therefore follow that our inferences, which are made in conformity to these laws, would only allow us to conceive and apprehend those thoughts and objects dependent on them. Of course, conforming to these laws would by no means imply that that which we cannot conceive of is non-existent. This is because, as I have demonstrated, that statement would only be relative to the laws it was made in accordance to. 


\section{God and Logically Impossible Tasks}

In virtue of what I have discussed so far, can we then imply that God can do the logically impossible? That is, can epistemic relativism be applied to the idea of God-and more specifically, to the notion of divine omnipotence in a manner that allows for God to do the logically impossible? To determine this, let us begin by the following intuitive thoughts on the matter: either it would be held that

God cannot do the logically impossible. In such a case God is constrained by the laws of logic (as well as time and space) just as His creation is; or,

God can do the logically impossible. In such a case we cannot conceive of such states of affairs (and how they can actualize).

Armed with the arguments that I have presented in favor of the epistemic relativist, I shall state the following reasons for the latter position:

(i) If our entire mode of thought is subject to certain laws, such as the laws of logic, it would follow that we cannot think otherwise. From this perspective the limitation of thought which we are bound by should not be supposed as one which lies in the object of our thought but rather in the thinking subject itself. Thus, if it is implied that according to the laws of logic God cannot accomplish tasks which defy this law (to which our thought is bound), it would be an incoherent statement. This is because when we make a claim of this kind it is based on a demonstrative statement and not a fact. It must be understood that no matter of fact can be a matter of demonstration.

What this means is that for 'demonstration' it would be essential that its object can be constructed from within. This would be a construct of the various forms inherent in our own mental constitution. Take thinking of a particular necessary truth, for example. It would fundamentally involve some cognitive activity in our minds. With the aid of the various experiences that we have acquired over a period of time, we are able to present a demonstrative formula which aims at substantiating the very necessary truth in question. This can only take place with me actually conceiving it to be so. Consequently, it is constructed internally. However, a fact is one that subsists independent of me thinking about it in any way. Let me take the same example I gave earlier about the planets revolving around the sun in elliptical orbits. This is a fact of nature. Regardless of anyone thinking about it or even failing to think about it, it would not influence its state of affairs in any way whatsoever. 
If we apply demonstrative matters in order to evaluate and determine God's omnipotence, then it would imply that this application would require us to construct a creature of the human imagination. Irrespective of the kind of God we end up envisaging in this regard, it would be an imaginative process that is bound by the very same laws with the aid of which we could only have formed and conceived of Him. Such an imitative process would be little more than conjured thoughts amalgamated in virtue of previously-acquired experiences in the course of our finite lives. This would be contrary to God's actual nature. For if God is absolute and infinite in His essence and His attributes, then our conception cannot apprehend Him in any sense. This is because human conception is only possible within the limits of possible intuition and experiential accumulation.

(ii) We may attempt to understand the finite limits of human apprehension from another perspective. Our thoughts are fundamentally subject to some sort of linear succession. (Regardless of whether you consider this a mental succession that is exclusively a product of the mind, or absolute, or even an ordered succession of events, it is nevertheless subject to the concept of time.) Every object which we can conceive of and be cognisant of is in some way subsisting through the passage of time. This is why we are able to distinguish a former state from its latter and vice versa, because that object occupies a particular interval in time. When an object succeeds from one state to another in the domain of time, and can be distinguished from its earlier state to its latter by the passage of time itself, then it is contingent and finite. The distinguishing feature between any two given states would be the duration and time that has elapsed. Even a pendulum which oscillates between two positions, however precise its return, would be distinguished from its former state by the passage of time.

Granting this temporal condition, time itself can be apprehended as finite since we can conceive of its parts in successive moments, allowing it to be divisible. We can conclude that all objects conceivable to humans must exist in time. Otherwise any object representing the true nature of the absolute or infinite could not be apprehended by the human mind. This would suggest that the true apprehension of God as an infinite and absolute divine being would be impossible for any human mind to truly (fully) apprehend. Therefore, if we fail to apprehend God, it would be absurd to suppose that $\mathrm{He}$ is unable to do the logically impossible-because something considered 'impossible' or even 'illogical' would be considered as such by human thought. It would not imply that that thing is 'impossible' in itself. 
(iii) We have previously discussed and concluded that the human mind is incapable of generating exclusively original thought. This is because we are constrained by particular laws of logic. Given this, attempting to construct a thought of God or even how He manages to accomplish particular acts which appear logically impossible to us, would result in the negation of thought altogether. It would follow that since we cannot apprehend God (in His true state) by employing our cognitive abilities within the limited confinements of the laws of logic, God must transcend the laws of logic. In other words, God is by no means constrained by such laws in His ability to either exist (in virtue of His essence and attributes alike) or act. For an epistemic relativist such a claim would not be incoherent or irrational. This is because any claim which infers that this is incoherent or irrational would be self-defeating in virtue of the God in question. The one who attempts to criticize the transcendence of God would have to resort to the laws of logic in some way to get off the ground. It is precisely this appeal to logical laws in virtue of the God in question where the epistemic relativist would gain the upper hand. However, if we imply that God is over and above logic, it does give rise to certain difficulties. I shall refer to two of these and provide a brief response to each.

1. It would entail that all logical (and rationally based) proofs of God's existence would become redundant; and

2. It would further mean that we cannot make any inferences about God at all on rational grounds. God would be unknowable and utterly unique.

In response to the first objection I would propose that we require a substantial revaluation of the role of logic in theological matters. This would primarily be an inquiry which seeks to determine questions such as those aptly raised by A.J. Cotnoir. For example, how should considerations of the limits of human reason influence our theological methodology? That is a central question spanning the history of theology, of course, but it is particularly pressing in the context of contemporary analytic theology. What is the role of logic in theology? What principles of logic are open to revision based on theological considerations (Cotnoir 2019, 508)?

To gain a broad view on the position of logic, Cotnoir proposes two opposing views: exceptionalism and anti-exceptionalism. Exceptionalism is the view that logic possesses a special status. It is analytic and always known a priori. Anti-exceptionalism is the view that logic does not possess any particular special status. It is not analytic, and isn't always known $a$ 
priori. Much of my discussion on epistemic relativism in this paper has clearly favored an anti-exceptionalist view of logic. I believe it is such a view which manages to articulate the correct role of logic in theological discourse. Since our thought processes are bound by the rules of logic, the latter should be applied to theological discourse in a procedural sense and not a substantive sense.

Acknowledging the limits of exceptionalism entails considering the following: an argument's soundness arises from having valid and true premises; and truth is itself dependent on statements that correspond to reality. It thus appears that the soundness of a logical argument would comprise of (1) demonstrative proofs and (2) facts or truths which correspond to reality. As mentioned earlier, demonstrative proofs that are based on argumentative forms, which possess the ability to prove particular cases, are not equivalent to truths based on correspondence to reality (facts). Demonstrative statements are a construct of the various forms inherent in our own mental constitution. Therefore, to exclusively apply demonstrative methods in order to arrive at a sound argument would be inadequate. As demonstration is confined to the limits in which our minds are able to think, it would not be plausible to apply such methods of reasoning in proving the existence of God in His true nature, as $\mathrm{He}$ is above logic and reason altogether.

We have shown that truth is relative to the variations in reference frames and conceptual schemas; and furthermore, that our minds are restrained by particular laws of logic. Consequently, we cannot conceive of any cases independent of experience. Given this, any logical argument we present would be also be relative. Therefore, logic itself would be relative to what we are, and the dimension to which we are referring. This should not be construed to discard the use of logic altogether. Instead, it should be taken as giving logic its rightful place. It attempts to show where logical arguments would fail to be applicable and why. In light of what we have mentioned so far, and in the absence of any alternative, it is impossible to simply reject logic-by which after all we are strictly bound and compelled to think.

The second objection states that if God transcends logic then we are unable to make any meaningful inferences about Him. God, in this sense, shall be unknowable to us. It should be made clear that this objection is not a demand for any specific argument for God's existence. Instead, it seeks to inquire how we are to make inferences of any kind about God without the appeal to logic. More specifically, it seeks to know how we can plausibly infer that God can or cannot do the logically impossible if He transcends logic. 
Let us first understand that since we cannot generate an exclusively original thought that is independent from experience, then we must have acquired the notion of God from somewhere. The subsisting idea of God in the conscious mind of man could not be said to have emerged solely from whim or imagination. The reason for this, as we have previously mentioned, is because the process of imagination combines known meanings and properties in random ways that are principally devoid of any systematic process. Therefore, in order for the imagination to be able to generate a true idea of God (that is, in His true sense) it must have the ability to apprehend absolute and infinite ideas (since God in His true sense is absolute and infinite). However, this is not possible, as we have demonstrated throughout our discussion. But then from where have we acquired this idea?

At this point in our inquiry we may choose to appeal to a (monotheistic) revealed religion. I suppose the appeal would specifically be towards that religion which is inclusive of the following advice:

God (great and glorious) is too exalted to be known by the intellect's [powers of] reflection and rational consideration (nazar). An intelligent person should empty his heart of reflection when he wants to know God by way of witnessing (mushāhada). The one with high aspiration should not learn this [kind of knowledge] from the world of imagination ('âlam al-khayāl), which contains embodied lights (al-anwär al-mutajassada) that point to meanings beyond them. For imagination causes intellectual meanings (almaānì al-'aqliyya) to descend into sensory forms (al-qawälib al-hissiyya), just as knowledge [appears] in the form of milk, the Qurān in the form of a rope, and religion in the form of a shackle. (Rustom 2014, 129)

\section{Conclusion}

In the course of this paper I have established that all human knowledge is relative. Furthermore, this relativity extends far enough to even include absolute and necessary truths. Therefore, when one makes the claim that God cannot perform logically impossible tasks because it would defy necessary truths such as the laws of logic-then this claim is only as correct and as valid as the one who asserts it, for man's mind is limited to the finite and submissive to the particular laws of logic. Therefore, the inferences made in conformity to the laws of logic would only allow us to conceive and apprehend those thoughts and objects dependent on them. However, the existence and compulsion in conforming to these laws would by no means imply that that which we cannot conceive of is non-existent. This is 
because, as we have demonstrated, that statement would only be relative to the laws it was made in accordance to.

Hence we learn the important lesson that the provinces of reason and faith are not coextensive; that it is a duty, enjoined by reason itself, to believe in what we cannot comprehend. (Mansel 2012, 247)

\section{Endnotes}

1. I refer in particular to two letters; the first addressed to Mersenne (dated April 15, 1630) and the second addressed to Henry More (written on February 5,1549$)$.

2. This view, however, is challenged by Richard R. LA Croix (1984), who argues that it is wrong to actually attribute this claim to Descartes. I will not dwell on this debate, but I will run with the general thought which is asserted by Harry Frankfurt (1977), who attributes to Descartes the belief that God is "a being for whom the logically impossible is possible."

3. This is a view that Tahko has defended, clearly stating that "I will also defend the status of LNC as the best candidate for a fundamental metaphysical principle-if there are any principles which constrain the structure of reality, then LNC is certainly our most likely candidate" (Tahko 2009, 32).

4. The so-called Bar-Hillel-Carnap paradox has already suggested, a half century ago, the clash between the notions of contradiction and semantic information: the less probable a statement is, the more informative it is, and so contradictions carry the maximum amount of information, and in the light of standard logic are, as a famous quote by Bar-Hillel and Carnap has it, "too informative to be true". This is a difficult philosophical problem for standard logic, which is forced to equate triviality and contradiction, and to regard all contradictions as equivalent, as the following example illustrates. If two auto technicians tell me that the battery of my car is flat, and its electrical system out of order, and add all the (potentially infinite) statements about car electrics, I have an excessive amount of information, including a huge amount of irrelevant information. Classically, this trivial amount of information is exactly the same as the information conveyed by the car technicians telling me a contradiction, such as the battery of my car is flat and that it is not flat. However, if one of the car technicians tells me (among his statements) that the battery is flat, and the other that the battery is not flat, between them they are contradictory, but now I know where the problem is! (Carnielli and Coniglio 2016, 2).

5. I am referring to a letter addressed to Mesland in which he makes mention of God not having any limits and our minds being finite. 
6. It should be noted here that upon this particular instance I have not referred to these statements as a priori analytic and synthetic statements, because I will pursue them as such shortly after. I do not intend to imply that both these notions of truth (i.e., first- and second-order statements and a priori analytic and synthetic statements) are essentially different in any way by discussing them apart. However, in doing so, I only hope to substantiate my position (that of the epistemological relativist) by providing two different replies for the same argument.

7. The notion of "logical space" was first introduced by Wittgenstein during his stay in Krakow in autumn 1914 while he was serving in the Austrian army. The considerations that finally led to the idea of an abstract space whose internal structure represents all the logic that underlies our ordinary language are well preserved in the first two wartime notebooks (MS 101, MS 102). They belong to a rapidly developing series of ideas which also includes an early version of the picture theory of proposition. They form an important part of the preliminary work for the Tractatus, the first draft of which-the so-called Prototractatus (preserved in MS 104)-Wittgenstein started to write down some time later in summer 1915 (Pilch 2017, 15-16).

8. FDE logic is probably the most versatile model of sub-classical logics, in the sense that it is inclusive of both paracomplete and paraconsistent systems. A logical theory is paracomplete if it recognizes a case $c$ such that $c \not 1 A$ and $c \not 0 A$, for some sentence $A$. Likewise, a logical theory is paraconsistent if it recognizes some case $c$ such that $c \vDash 1 A$ and $c \vDash 0 A$, for some $A$. The terms "paracomplete" and "paraconsistent", from the Greek word "para” (beyond), imply that we are moving beyond having only complete or consistent cases (Beall and Logan 2017, 178-179). The consequence of being both paracomplete and paraconsistent is that it does not impose exhaustion and exclusion (respectively) on its predicates. Classical logic, conversely, imposes both exhaustion and exclusion, significantly constraining its interpretative power with respect to predicates. Imposing exhaustion means that classical logic does not recognize any possible instance in which an object fails to be in either extension or anti-extension of a predicate. In such cases there is no possible instance in which a predicate fails to be either true or false of an object. Imposing exclusion means that classical logic does not recognize a possible instance in which an object falls into both the extension and anti-extension of a predicate. In such cases there is no possible instance in which a predicate is both true and false of an object. As a result of this classical logic is only admitting of cases that are complete and consistent. This eliminates the possibility of entertaining truth-value gaps and gluts.

This is where FDE logic has a greater advantage. By being paracomplete and paraconsistent, FDE logic is able to entertain the maximum available truth-values, in contrast to both classical and alternative sub-classical logics. A paracomplete theory is able to sustain some meaningful and declarative 
statements that are neither true nor false, that is, statements which are referred to as "gappy". A paraconsistent theory is able to sustain some meaningful and declarative statements that are both true and false, that is, statements which are referred to as "glutty".

9. This attitude has not merely persisted as part of the intellectual legacy, but is actively reasserted as "an entrenched 'unassailable dogma' of Western thought” (Beall 2004, 3).

10. Exceptions can be found in Western intellectual history, although

With the exception of Hegel and his fellow-travellers, and whilst Aristotle's opinion on nearly every other matter has been overturned-or at least challenged-nearly every Western philosopher and logician has accepted the authority of Aristotle on this matter. There is hardly a defence of the Law since Aristotle's, worth mentioning. (Priest 2006, 7)

However, attempting to locate personalities or remote instances to this end within Islamic intellectual history proves unviable. After failing to find some material/resources on this matter, I contacted four foremost historians of Islamic philosophy and logic (Khaled El-Rouayheb, Tony Street, Peter Adamson, and Ahmed Alwishah). I asked whether they could kindly direct me to some reading material on Arabic logicians who attempted or actually engaged with a system of logic while either rejecting the law of non-contradiction and/or considering the principle of explosion to be invalid. In their responses, though they noted the importance of the inquiry, they could not suggest any secondary literature or Arabic logicians who questioned the principle of non-contradiction outright. (El-Rouayheb did comment that some scholars who discussed the liar paradox were willing to suggest that 'What I say is false' is both true and false, though this appears to have been a minority opinion.)

11. "According to Ibn Sīnā, a demonstration transfers truth, certainty and necessity from the premises to the conclusions. Premises or first principles are generally divided into two parts, the first principles for all sciences are called common principles (al-ușūl al-muta'ärafa), and the first principles for every special science called postulates (al-ușūl al-mawḍūa). For example, "whole is bigger than [its] part" or "contradiction is impossible", etc are common principles, and "the shortest line between two points is a straight line" is a postulate for the science of geometry. Ibn Sinnā has a vast investigation in his different writings on the ways common principles are acquired by the mind. A class of these common principles the called as awwaliyyāt, are acquired only through the intellective faculty. These are propositions that are obvious for the intellective faculty and accepting them is necessary. The above two examples of the common principles are of this category. Contrary to the 
common principles, which are certain, the postulates are susceptible of doubt (mashkūk)" (Ardeshir 2008, 58).

12. "This, it seems to me, provides the strongest reason for according default status to classical logic, for-with only one class of exceptions-classically valid arguments conform to our intuitive sense of deductions whose conclusions follow from their premisses. Setting aside the exceptions, the classical natural deduction rules seem, when we first meet them, to codify norms of deductive reasoning that we have implicitly followed for years" (Rumfitt 2015, 15).

13. "Weininger, however, thinks that obeying the laws of logic is something we ought to do precisely because it belongs to the strict moral duties we have toward ourselves. He thereby holds that logic is intrinsically categorically normative (and thus falls under $4 \mathrm{~A}$ ), but for reasons quite different from those found in the moral science conception of logic. According to the moral science conception, logic is intrinsically categorically normative because it is based on rationality itself (hence rationality is intrinsic to logic) and is also an integral part of human morality, namely the part that consists in justifying moral judgments and decisions, including direct moral arguments and reflective equilibrium" (Hanna 2006, 205-206).

14. "It is important to distinguish between laws of science and laws of nature. Laws of nature are those empirical regularities which govern the natural world around us, irrespective of whether or not intelligent beings possess knowledge of these regularities or whether or not an appropriate symbolic representation for at least some of these regularities has been developed... Laws of science, by contrast, are those regularities of the natural world which are known to us and which have been cast in appropriate symbolic forms. Laws of science may be subject to various kinds of modification" (Weinert 1995, 4-5).

15. I refer to this statement because it can be said to be an "absolute truth" as well as a necessary truth, where it is not only true in every possible world but further is conceived as such by every possible conceiver.

\section{References}

Adams, R.M. 1987. “Divine Necessity." In The Concept of God. Edited by Thomas V. Morris. Oxford: Oxford University Press.

Ahsan, A. 2017. "A Realist Approach in Analytic Theology and the Islamic Tradition." Philosophy and Theology 29, no. 1: 101-132.

Ahsan, A. 2018. "The Classical Correspondence Theory of Truth and the God of Islam." Philosophy and Theology 30, no. 2: 273-294.

Ahsan, A. 2019. "Quine's Ontology and the Islamic Tradition." American Journal of Islamic Social Sciences 36, no. 2: 20-63. 
Ahsan, A. 2019. “The Paradox of an Absolute Ineffable God of Islam.” Philotheos 19: 227-259.

Ardeshir, M. 2008. "Ibn Sīnās Philosophy of Mathematics." In The Unity of Science in the Arabic Tradition: Science, Logic, Epistemology and their Interactions. Edited by S. Rahman, T. Street and H. Tahiri. New York: Springer. 43-62.

Baghramian, M. 2010. “A Brief History of Relativism." In Relativism: A Contemporary Anthology. Edited by M. Krausz. New York: Columbia University Press.

Baghramian, Maria and Carter, J. Adam. 2019. "Relativism." In The Stanford Encyclopedia of Philosophy (Winter Edition). Edited by Edward N. Zalta. https:// plato.stanford.edu/archives/win2019/entries/relativism/.

Beall, J. 2004. "At the Intersection of Truth and Falsity." In The Law of Non-Contradiction: New Philosophical Essays. Edited by G. Priest, J. Beall, and B. Armour-Garb. Oxford: Oxford University Press. 1-22.

Beall, J. and Logan, S. 2017. Logic: The Basics. 2nd ed. Oxford: Routledge.

Blackburn, S. 2010 [2005]. “Conceptual Schemes.” In Relativism: A Contemporary Anthology. Edited by M. Krausz. New York: Columbia University Press.

Brink, G.V.D. 1993. “Descartes, Modalities, and God.” Philosophy of Religion 33, nos. 1-15: 8 .

Carnielli, W. and Coniglio, M. 2016. Paraconsistent Logic: Consistency, Contradiction and Negation. Switzerland: Springer International Publishing.

Cotnoir, A. 2018. "Logical Nihilism." In Pluralisms in Truth and Logic. Edited by J. Wyatt, N. Pedersen and N. Kellen. Switzerland: Palgrave Macmillan. 301329.

Cotnoir, A. 2019. "On the Role of Logic in Analytic Theology: Exploring the Wider Context of Beall's Philosophy of Logic." Journal of Analytic Theology 7, no. 1: 508.

Croix, R.R. 1984. "Descartes on God's Ability to do the Logically Impossible." Canadian Journal of Philosophy 14, no. 3: 455-475.

Davidson, D. 2010 [1973-1974]. "On the Very Idea of a Conceptual Scheme." In Relativism: A Contemporary Anthology. Edited by M. Krausz. New York: Columbia University Press.

Frankfurt, H. 1977. "Descartes on the Creation of Eternal Truths." The Philosophical Review, 86: 44.

Goldman, A.I. 2008 [1976]. “What Is Justified Belief?” In Epistemology: An Anthology. Edited by E. Sosa, J. Kim, J. Fantl, and M. Mcgrath. Oxford: Blackwell Publishing.

Grim, P. 2004. "What is a Contradiction?" In The Law of Non-Contradiction: New Philosophical Essays, edited by G. Priest, J. Beall and B. Armour-Garb, 49-72. Oxford: Clarendon Press.

Hanna, R. 2006. Rationality and Logic. Cambridge, Massachusetts: MIT.

Kant, I. 1996 [1781-1787]. Critique of Pure Reason. Translated by W.S. Pluhar. USA: Hackett Publishing Company, Inc. 
Krausz, M. 2010. “Mapping Relativism.” In Relativism: A Contemporary Anthology. Edited by M. Krausz. New York: Columbia University Press.

Locke, J. 2015. An Essay Concerning Human Understanding. Wordsworth Editions Ltd.

Luper, S. 2004. “Epistemic Relativism.” Philosophical Issues 14: 271-295.

Mansel, H.L. 1860. The Limits of Religious Thought Examined in Eight Lectures Delivered Before the University of Oxford, in the Year Mdccclviii., On the Bampton Foundation, USA: University of Michigan Library.

Mansel, H.L. 2012 [1871]. Metaphysics, Or The Philosophy Of Consciousness, Phenomenal And Real. Forgotten Books.

Mansel, H.L. 2012 [1860]. Prolegomena Logica: An Inquiry Into The Psychological Character of Logic. Forgotten Books.

Margolis, M. 2010 [1989]. “The Truth About Relativism.” In Relativism: A Contemporary Anthology. Edited by M. Krausz. New York: Columbia University Press.

Morris, M. 2008. Routledge Philosophy Guidebook to Wittgenstein and the Tractatus. Hoboken: Taylor \& Francis.

Peregrin, J. 2020. Philosophy of Logical Systems. Oxon: Routledge.

Pilch, M. 2017. “The Structure of Wittgenstein's Logical Space.” Wittgenstein-Studien 8, no. 1: 15-60.

Popper, K. 1963. The Logic of Scientific Discovery. Oxford: Oxford University Press.

Priest, G. 2006. Doubt Truth to be a Liar. Oxford: Oxford University Press.

Putnam, H. 1994. "Sense, Nonsense, and the Senses: An Inquiry into the Powers of the Human Mind." The Journal of Philosophy 91, no. 9: 445.

Rumfitt, I. 2010. "Logical Necessity." In Modality Metaphysics, Logic, and Epistemology. Edited by B. Hale and A. Hoffmann, 35-64. Oxford: Oxford University Press.

Rumfitt, I. 2015. Boundary Stones of Thought. Oxford: Oxford University Press.

Runzo, J. 1986. Reason, Relativism and God. London: Macmillan Press.

Russell, G. 2018. "Logical Nihilism: Could There Be No Logic?” Philosophical Issues 28 , no. 1: 308-324.

Rustom, M. 2014. "Ibn 'Arabī’s letter to Fakhr Al-Dīn Al-Rāzī: A Study and Translation." Journal of Islamic Studies 25, no. 2: 113-137.

Sher, G. 2016. "Substantivism about Truth." Philosophy Compass 11, no. 12: 818-828.

Shirreff, and Weatherson, B. 2017. "Relativism." In A Companion to the Philosophy of Language. Edited by B. Hale, C. Wright and A. Miller. 2nd ed. Chichester: Blackwell Publishing Ltd. 787-803.

Siegel, H. 1986. "Relativism, Truth, and Incoherence." Synthese 68, no. 2: 225-259.

Swinburne, R. 1977. The Coherence of Theism. Oxford: Clarendon Press.

Tahko, T. 2009. "The Law of Non-Contradiction as a Metaphysical Principle." The Australasian Journal of Logic 7.

Zolghadr, B. 2019. "Avicenna on the Law of Non-contradiction." History and Philosophy of Logic 40, no. 2: 105-115. 